\title{
Substrate Effects on Crystal Phase in Atomic Layer Deposition of Tin Monosulfide
}

\author{
Oleksandr V. Bilousov, Andrii Voznyi, Björn Landeke-Wilsmark, Michelle Marie S. Villamayor, \\ Tomas Nyberg, and Carl Hägglund*
}

Cite This: Chem. Mater. 2021, 33, 2901-2912

Read Online

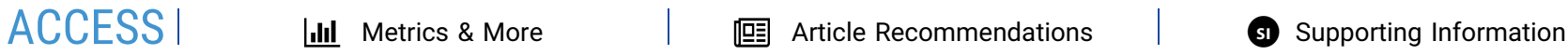

ABSTRACT: Obtaining single-phase tin monosulfide ( $\mathrm{SnS}$ ) films at low temperatures is challenging since cubic $(\pi$-SnS) and orthorhombic $(\alpha-\operatorname{SnS})$ polymorphs have similar energies of formation and grow under similar conditions. Here, we show that in atomic layer deposition (ALD) of polycrystalline $\mathrm{SnS}$ using tin(II) acetylacetonate and $\mathrm{H}_{2} \mathrm{~S}$ precursors, the substrate surface greatly influences the $\mathrm{SnS}$ phase evolution. For example, a silicon (100) substrate, with a highly hydroxylated surface, favors the growth of $\alpha$-SnS. Meanwhile, ozone treatment or preannealing of the same substrate leads to mainly $\pi$-SnS. Just a few ALD cycles of another oxide or sulfide can even more substantially alter the outcome. Substrates that favor $\alpha$-SnS growth typically
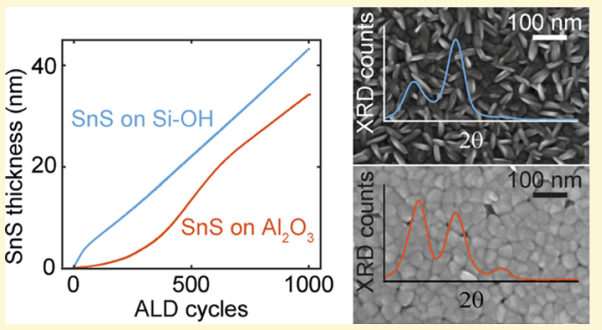
produce initially enhanced growth rates, while those promoting $\pi$-SnS are partially surface-poisoned by the acetylacetonate precursor ligands. Growth of either polymorph is self-sustained after its initiation, and the sustaining factor appears to be the surface-ligand interaction; $\pi$-SnS preferentially evolves on substrates and $\pi$-SnS surfaces that are rich in highly reactive dangling bonds, while chemically inert substrates and $\alpha$-SnS surfaces promote $\alpha$-SnS. While lattice matching is less central, the role of ligand bonding in SnS ALD also helps explain the previously reported phase dependence on growth temperature and $\mathrm{H}_{2} \mathrm{~S}$ precursor dose and shows promise for area-selective ALD of SnS.

\section{INTRODUCTION}

Tin monosulfide ( $\mathrm{SnS}$ ) has optoelectronic properties of interest for a broad range of applications. It is attractive for low-cost, thin film photovoltaics, as it contains only nontoxic and earth-abundant elements. ${ }^{1} \mathrm{SnS}$ is also a relatively simple binary compound, facilitating its efficient and inexpensive production. In its naturally occurring Herzenbergite form, it has a high absorption coefficient, high carrier mobility, and band gap energies of 1.1 and $1.3 \mathrm{eV}$ for indirect and direct transitions, respectively. ${ }^{2,3}$ Herzenbergite has an orthorhombic unit cell and is composed of layers stacked along the $b$-axis. The layers are loosely bound by van der Waals forces and are candidate two-dimensional materials with interesting properties for valleytronics. ${ }^{4}$ The orthorhombic polymorph of $\mathrm{SnS}$ $\left(\alpha\right.$-SnS) can be grown as nanosheets along the $b$-axis ${ }^{5}$ and as nanoribbons along the $a$ - and $c$-axes with terminating facets of (100) and (001) planes. ${ }^{6}$ It is further of high interest for fieldeffect transistors, ${ }^{7}$ photodetectors, ${ }^{8}$ plasmonic solar cells, ${ }^{9}$ and lithium battery applications. ${ }^{5}$ However, the anisotropy of $\alpha$ $\mathrm{SnS}$ may lead to band edge fluctuations and voltage losses in solar cells, which has been considered one limitation to the achievable photovoltaic conversion efficiency. ${ }^{10}$ In contrast, this is not an issue for the less explored cubic crystal structure termed $\pi$-SnS, ${ }^{11,12}$ with its large $(11.7 \AA)$ isotropic unit cell consisting of 64 atoms. Similar to $\alpha$-SnS, the $\pi$-SnS phase displays a high absorption coefficient in the visible range, but it has a wider band gap of direct forbidden-type between 1.6 and
$1.7 \mathrm{eV} .^{13,14}$ This band gap is close to ideal for the top cell of tandem solar cells with silicon or other narrow band gap bottom cells and may also provide the required chemical potential for photocatalytic reactions not accessible with narrower band gap semiconductors. The unusual band structure of $\pi$-SnS, associated with its chiral symmetry group, may also be of interest for applications in nonlinear optics. ${ }^{15}$

The self-limiting nature of atomic layer deposition (ALD) allows for precise thickness and compositional control and conformal coating of structures with high aspect ratios, which makes it particularly attractive for surface and interfacial engineering of electronic and optoelectronic devices. ${ }^{16,17}$ ALD of $\mathrm{SnS}$ films was first reported by Kim et al. using the commercially available precursor tin(II) acetylacetonate [Sn$\left.(\mathrm{acac})_{2}\right] .{ }^{18}$ Other $\mathrm{Sn}$ precursors have subsequently also been deployed for SnS ALD. 3,19,20

In our previous work, we found that variation of the ALD growth conditions allows control over the polymorphism, morphology, and optical properties of grown SnS thin films. In particular, through variation of substrate temperature and dose

Received: January 22, 2021

Revised: March 23, 2021

Published: April 16, 2021 
of the $\mathrm{H}_{2} \mathrm{~S}$ counter reactant, we produced films ranging from more or less pure $\pi$-SnS to $\alpha$-SnS. ${ }^{14}$ However, we also demonstrated that changing the $\mathrm{H}_{2} \mathrm{~S}$ dose resulted in slight variations of the $\mathrm{SnS}$ stoichiometry, with consequences for defect formation and possibly doping levels. ${ }^{21}$

The substrate surface is an additional factor that may affect the SnS thin film growth. ${ }^{22}$ Effects of the substrate on the grain size of $\mathrm{SnS}$ grown by chemical vapor deposition (CVD) were previously observed by Ahmet et al. ${ }^{23}$ Moreover, in solutionbased $\mathrm{SnS}$ deposition, Abutbul and Golan recently demonstrated preferential $\alpha$-SnS growth after oxide removal from a GaAs substrate, while epitaxial $\pi$-SnS growth was observed on $\mathrm{PbS}$ and ascribed to a combination of lattice matching and surface chemistry. ${ }^{24}$

In the present work, we investigate the influence of the substrate on the properties of $\mathrm{SnS}$ films grown in vacuum by low-temperature ALD using $\mathrm{Sn}(\mathrm{acac})_{2}$ and $\mathrm{H}_{2} \mathrm{~S}$ as precursors. By characterizing the growth on $\mathrm{Si}(100)$ and various other substrates [see further Table S1 of the Supporting Information (SI)], we elucidate the initial surface processes and growth modes. We show that it is the chemical properties of the substrate, rather than the lattice constants of exposed surface planes, that determine the grown $\mathrm{SnS}$ crystal phase. The substrate-induced $\mathrm{SnS}$ phase can be self-sustained over at least 1000 ALD cycles and produce more or less phase-pure, polycrystalline films of either type. An approximate relationship is established between the logarithmized initial growth rate per cycle, determined by in situ spectroscopic ellipsometry, and the final phase composition. We demonstrate that substrate modification by a few ALD cycles of certain materials, such as $\mathrm{Al}_{2} \mathrm{O}_{3}$ or $\mathrm{ZnS}$, is enough to change the growth trajectory from mainly $\alpha$-SnS to $\pi$-SnS, or vice versa. On other substrates, strongly suppressed growth is observed. In the latter category, $\mathrm{Au}$ - and $\mathrm{SnS}_{2}$-coated substrates are given particular attention.

\section{MATERIALS AND METHODS}

Thin Film Growth by ALD. The SnS deposition was carried out using a viscous flow, hot wall reactor (Picosun R-200 Advanced ALD system) on $\mathrm{Si}(100)$ substrates (phosphorus doped, $1-10 \Omega \mathrm{cm}$, Sil'tronix) that were cleaned and modified as described further below and in Table $\mathrm{S} 1$ of the Supporting Information. Nitrogen gas $\left(\mathrm{N}_{2}\right.$, 99.9999\%, Air Liquide) was used as the carrier gas for the ALD precursors. The base flow of $\mathrm{N}_{2}$ was 420 SCCM, which resulted in a reactor pressure of about $8 \mathrm{hPa}$. Tin(II) acetylacetonate (SigmaAldrich 99.9\%) and hydrogen sulfide (Air Liquide, 99.5\%) were used as precursors. The substrate and reactor chamber were maintained at a temperature of $120{ }^{\circ} \mathrm{C}$. The cartridge with $\mathrm{Sn}(\mathrm{acac})_{2}$ was maintained at $100{ }^{\circ} \mathrm{C}$ to provide sufficient vapor pressure of the liquid precursor and, hence, conditions for saturated $\mathrm{SnS}$ growth. Our standard ALD cycle consisted of a stop-flow sequence of (1) reduced carrier gas flow, (2) reduced pumping speed through a bypass constriction, (3) precursor injection, (4) precursor exposure, (5) restored pumping speed, and (6) restored carrier gas flow and purging. For the $\mathrm{Sn}(\mathrm{acac})_{2}$ precursor, the durations of steps $1-6$ were $2,1,1.4,1.6,2$, and 3 s. During this sequence, the carrier gas flow was reduced from 50 to $10 \mathrm{SCCM}$ in each of the five unused precursor lines of the system. The $\mathrm{Sn}(\mathrm{acac})_{2}$ line used a flow of $160 \mathrm{SCCM}$ apart from a brief $(1.2 \mathrm{~s})$ boost of 400 SCCM during the injection step. In the $\mathrm{H}_{2} \mathrm{~S}$ half-cycle, the durations of steps $1-6$ were $1,1,1,2$, 1 , and $3 \mathrm{~s}$, while the flow of carrier gas in the $\mathrm{H}_{2} \mathrm{~S}$ line was maintained at 120 SCCM. A few experiments were also performed in another ALD reactor (Microchemistry F-120). The general process conditions were comparable to those above (the same precursors and substrate temperature) and were described in more detail in a previous publication. $^{14}$
Vacuum Annealing. $\mathrm{Si}(100)$ substrates were cleaned using a standard cleaning solution ( $\mathrm{SCl} ; 1 \quad \mathrm{NH}_{4} \mathrm{OH}: 1 \quad \mathrm{H}_{2} \mathrm{O}_{2}: 20 \quad \mathrm{H}_{2} \mathrm{O}$ by volume) to produce a clean silicon surface with oxide termination. ${ }^{25}$ After rinsing with deionized water, a close to fully hydroxylated surface $(\mathrm{Si}-\mathrm{OH})$ can be expected, with approximately $4.7 \mathrm{OH}$ groups $/ \mathrm{nm}^{2}{ }^{26}$ The $\mathrm{Si}-\mathrm{OH}$ samples were loaded into the ALD reactor, which was then evacuated to a pressure of around $8 \mathrm{hPa}$ of $\mathrm{N}_{2}$. In experiments to determine the role of surface hydroxylation for the SnS ALD, substrates were annealed in situ, prior to ALD. After a temperature ramping time of between 30 and $60 \mathrm{~min}$, annealing was performed for $1 \mathrm{~h}$, at temperatures of 300,400 , and $500{ }^{\circ} \mathrm{C}$, respectively. After cooling to $120{ }^{\circ} \mathrm{C}, 1000$ cycles of SnS ALD were performed as described above. Samples that were not annealed were heated to $120^{\circ} \mathrm{C}$ and left for $1 \mathrm{~h}$ prior to the SnS ALD.

Spectroscopic Ellipsometry. A spectroscopic ellipsometer (Woollam RC2-X with near-infrared extension) was used at a fixed angle of incidence of $61^{\circ}$ for in situ monitoring of the evolving thickness and optical properties of the films during ALD. Measurements were performed at time intervals in the range of 2-10 s, collecting the two standard ellipsometric variables $(\Psi, \Delta)$ along with depolarization data over 1065 wavelengths from 210 to $1690 \mathrm{~nm}$. Data analysis was performed with CompleteEase software.

To capture the evolving film properties, an adaptive multilayered optical model for the samples was developed. As substrates, the model used the temperature-dependent optical constants of $\mathrm{Si}$ at the deposition temperature $\left(120^{\circ} \mathrm{C}\right)$ from tabulated data provided by the instrument manufacturer. The $\mathrm{Si}$ oxide layer was also modeled using tabulated data, but its thickness (typically 15-20 ̊) was established from in situ measurements performed just prior to the ALD. Measurement data was collected before and throughout the entire ALD growth process. In the analysis of the data, grown films were represented as one or more stratified layers parallel to the substrate plane. The permittivity of each of these layers was modeled by oscillators, with the imaginary part obtained from a superposition of multiparameter oscillator functions and the real part as the KramersKronig transform of the imaginary part. Additional contributions to the latter were included through constant offset and poles located in the ultraviolet and infrared, representing optical transitions outside the measured range. For the (effective) optical constants of few-cycle $\mathrm{Al}_{2} \mathrm{O}_{3}$ films, a single pole in the UV region was fitted. For SnS films grown by 1000 ALD cycles, a three-layer model was employed. The properties of the bottom and middle parts of the SnS layer were each fitted using a polynomial spline oscillator (the psemi-m0 oscillator) along with four Gaussian oscillators. The top layer used the Bruggeman effective medium approximation (EMA) for a mixture of vacuum and middle layer properties to represent the roughness and surface layers. To determine the optical constants of each layer, a multisample analysis of the SnS film was performed for at least 10 time slices sampled from the growth data, such that ellipsometric spectra from all different stages of the film growth were included. The $\mathrm{SnS}$ oscillator parameters were jointly fitted for all time points, while the thicknesses of the three layers and the filling factor of the EMA layer were allowed to vary with time and thus with the number of ALD cycles. After establishing the effective optical properties of each layer in this way, a dynamic fit of the thicknesses and EMA filling factors was performed for all data to increase the time resolution of the growth curves. The middle SnS layer ended up as the thickest layer in the final films and arguably represents the bulk $\mathrm{SnS}$ properties most closely as it is least affected by the interfaces. An example of the layered model used in the ellipsometric data analysis is included in Figure S1 of the Supporting Information. The optical constants of this layer typically agreed relatively well with our previous results for $\alpha$ and $\pi$-SnS by ALD. ${ }^{14}$ Note, however, that the optical constants obtained here are derived from a compromise of fitting the $\mathrm{SnS}$ film at different stages of its growth and should not be expected to agree perfectly with an analysis based on ex situ measurements on the fully grown film at variable angles of incidence. The mean squared error of the model fit was typically in the range from 1 to 3 over the entire growth process. This, together with the reasonable agreement with $e x$ situ results, suggests that accurate solutions were obtained. 

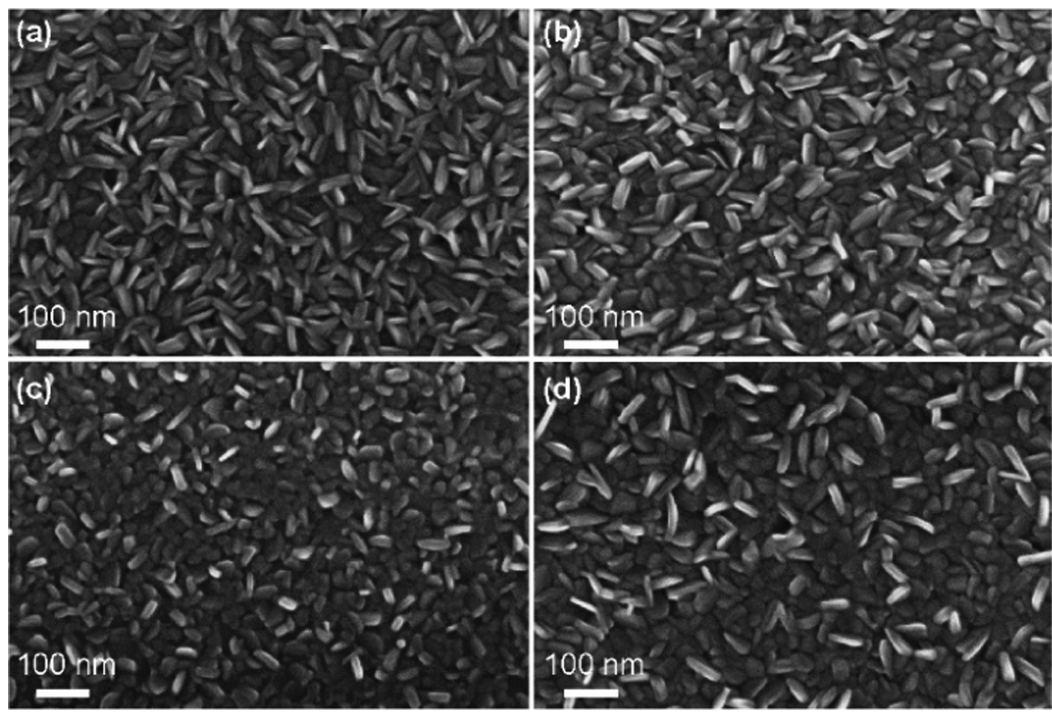

Figure 1. SEM images of $\mathrm{SnS}$ thin films on $\mathrm{Si}-\mathrm{OH}$ after 1000 cycles of $\mathrm{ALD}$ performed at $120^{\circ} \mathrm{C}$ after (a) equilibration for $1 \mathrm{~h}$ at $120^{\circ} \mathrm{C}$ and after $1 \mathrm{~h}$ preannealing at (b) $300{ }^{\circ} \mathrm{C}$, (c) $400{ }^{\circ} \mathrm{C}$, and (d) $500{ }^{\circ} \mathrm{C}$.

Microscopy. The surface morphologies of the films were examined by field-emission scanning electron microscopy (SEM) using a Zeiss 1550 , an acceleration voltage of $10 \mathrm{kV}$, and a working distance between 4 and $5 \mathrm{~mm}$.

Grazing-Incidence X-ray Diffraction. Grazing-incidence X-ray diffraction (GI-XRD) was carried out using a Siemens D5000 equipped with an X-ray mirror and a parallel plate collimator. $\mathrm{Cu} \mathrm{K-} \alpha$ radiation $(8.05 \mathrm{keV})$ was used at a fixed angle of incidence of $0.5^{\circ}$. The powder diffraction files used for references were that of mineral herzenbergite for $\alpha-\mathrm{SnS}^{27}$ and that of the large cubic tin monosulfide polymorph for $\pi$-SnS. ${ }^{28}$

Raman Spectroscopy. Raman scattering measurements were performed in a Renishaw inVia confocal Raman microscope. A laser wavelength of $532 \mathrm{~nm}$ was used with a power of $0.2 \mathrm{~mW}$ for excitation, and a microscope lens with a numerical aperture of 0.35 was used.

\section{RESULTS AND DISCUSSION}

Effect of Hydroxylation. SnS films deposited at $120{ }^{\circ} \mathrm{C}$ either directly on a clean $\mathrm{Si}-\mathrm{OH}$ substrate or on vacuumannealed $\mathrm{Si}-\mathrm{OH}$ have differences in film morphology as revealed by SEM imaging (Figure 1). Films deposited on Si$\mathrm{OH}$ displays elongated, bladelike grains of random orientation typical for $\alpha$-SnS. ${ }^{14}$ In contrast, films deposited on substrates after annealing at $500{ }^{\circ} \mathrm{C}$ have a lower density of protruding $\alpha$ $\mathrm{SnS}$ grains on the surface, beneath which a more densely packed layer of smaller grains can be discerned. The latter has previously been associated with the $\pi$-SnS polymorph, ${ }^{14}$ suggesting that $\pi$-SnS growth is favored over $\alpha$-SnS with increasing preannealing temperature of the $S$ i substrate.

To confirm this, the crystal structure was studied by GI$\mathrm{XRD}$ at $0.5^{\circ}$ angle of incidence. With a $\mathrm{SnS}$ density of about $5.1 \mathrm{~g} / \mathrm{cm}^{3}$, the X-ray attenuation length defined normal to the surface can, in this case, be estimated ${ }^{29}$ as around $60 \mathrm{~nm}$. This exceeds the $\mathrm{SnS}$ film thickness, which means that reflections are collected from the whole SnS film, while the peak-to-noise ratio is much enhanced compared to normal incidence due to the extended X-ray path length through the film. GI-XRD patterns recorded for different $\mathrm{Si}$ preannealing temperatures are given in Figure $2 \mathrm{a}$ on an expanded scale for $2 \theta$ from 30 to $35^{\circ}$. The GI-XRD data reveals a high degree of crystallinity of the ALD SnS films and a polycrystalline structure that varies
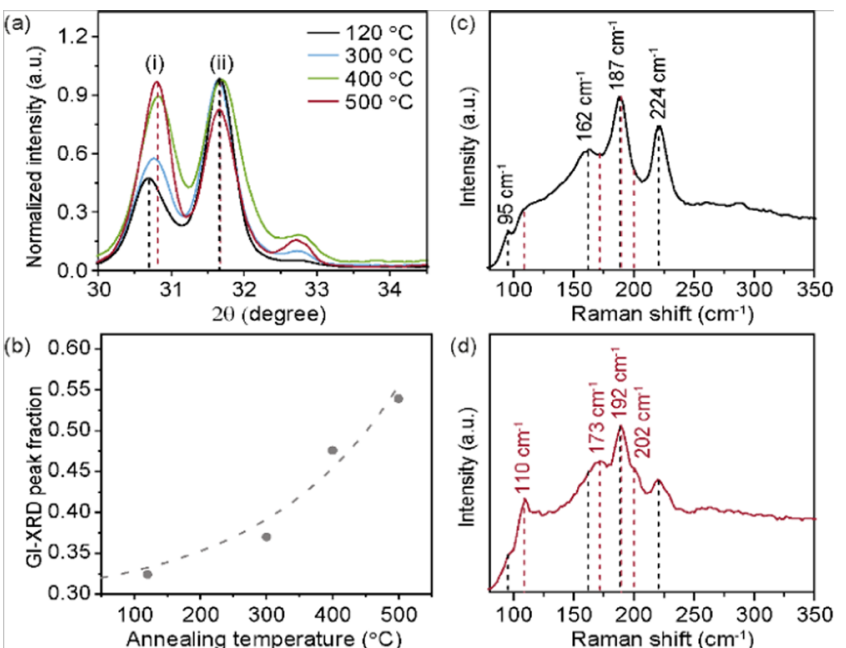

Figure 2. (a) GI-XRD patterns of SnS thin films prepared by ALD (1000 cycles) on $\mathrm{Si}$ after vacuum annealing at varying temperatures. (b) GI-XRD peak fraction $[\mathrm{i} /(\mathrm{i}+\mathrm{ii})]$ versus annealing temperatures. (c) Raman spectrum measured for $\mathrm{SnS}$ films with no annealing and (d) after annealing at $500{ }^{\circ} \mathrm{C}$.

with the Si substrate temperature treatment. The sample that was annealed at $500{ }^{\circ} \mathrm{C}$ has $2 \theta$ peak positions at $30.8,31.7$, and $32.7^{\circ}$, which are very close to the reference peaks of pure $\pi$ SnS and correspond to the (400), (410), and (411) Miller indices, respectively. ${ }^{28}$ For the nonannealed $\mathrm{Si}-\mathrm{OH}$ substrate, on the other hand, the two peaks at 30.6 and $31.6^{\circ}$ are most pronounced. These are close to the reference peaks at 30.5 and $31.5^{\circ}$ for the (101) and (111) planes of $\alpha$-SnS, respectively. ${ }^{27}$ To obtain a relative measure of the phase composition in the films, one may study the relation between peaks (i) and (ii) labeled in Figure 2a, as captured in the peak intensity ratio "i/ $(i+i i) "{ }^{14}$ This peak fraction increases with the Si preannealing temperature, as shown in Figure $2 b$, which is consistent with increasing content of cubic-phase $\mathrm{SnS}$ in the films. ${ }^{14}$ In addition, shifts of both peaks (i) and (ii) are observed, associated with changes of the (average) lattice parameters. 
The clear development of the (411) peak at $32.7^{\circ}$ provides further evidence of increased cubic-phase content.

Raman characterization was performed to provide further confirmation of the $\mathrm{SnS}$ phase dependence. Spectra were collected for the $\mathrm{SnS}$ films grown on $\mathrm{Si}-\mathrm{OH}$ without annealing and on $\mathrm{Si}-\mathrm{OH}$ after annealing at $500{ }^{\circ} \mathrm{C}$ (Figure 2c,d). Without annealing, peaks are found at 95, 162, 187, and 224 $\mathrm{cm}^{-1}$, which all match with those of previous reports related to $\alpha$-SnS. ${ }^{30,31}$ After annealing, Raman peaks associated with $\pi$ SnS, notably at 110, 173, and $202 \mathrm{~cm}^{-1}$, dominate the spectrum. Based on the results from SEM, GI-XRD, and Raman spectroscopy, we thus conclude that on hydroxylated $\mathrm{Si}(100)$, vacuum annealing favors the growth of $\pi$-SnS over $\alpha$ $\mathrm{SnS}$. Annealing increases the surface energy of the substrate through a reduced number of $\mathrm{OH}$ groups, as illustrated by Figure 3. The dependence of the GI-XRD peak fraction of the

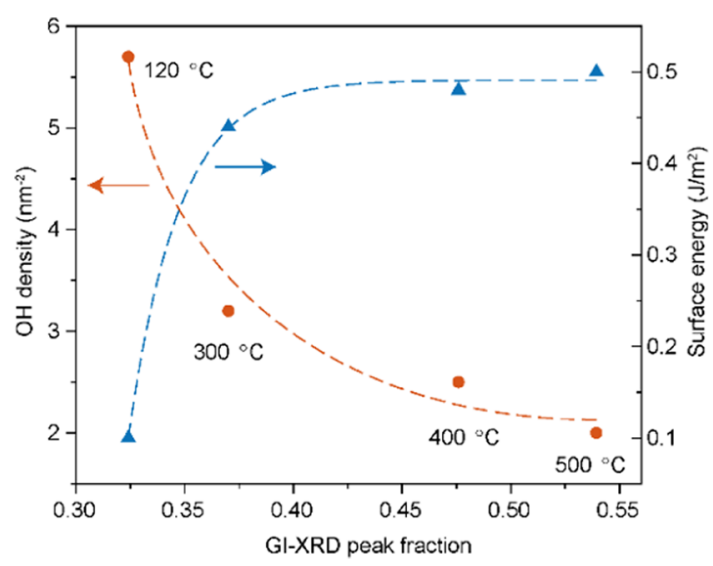

Figure 3. Approximate density of $\mathrm{OH}$ groups (left $y$-axis) after annealing the Si substrate at different temperatures, together with the corresponding surface energy of the Si substrate (right $y$-axis). ${ }^{26,33}$ The GI-XRD peak fraction is a proxy for the resulting phase mixture of the grown SnS film, with higher values indicating higher contents of $\pi$-SnS compared to $\alpha$-SnS.

grown SnS film on the substrate annealing temperature may thus be connected to the higher surface energy, where a lower $\mathrm{OH}$ density and higher surface energy favor the $\pi$-SnS growth.

The surface and bulk free energies of growing films generally play a decisive role in their growth behavior, the resulting crystal structure, and texture. Films tend to grow to minimize the total free energy of the bulk and exposed surface planes and thereby approach the thermodynamic equilibrium. Abutbul et $\mathrm{al}^{32}$ recently presented density functional theory (DFT) calculations for both $\pi$ - and $\alpha$-SnS and their most commonly exposed facets. While the bulk energies of the two phases are similar and make negligible difference to the total free energy at the initial stages of film growth, the (010) facet of $\alpha$-SnS displays substantially lower surface energy than any facets of $\pi$ $\mathrm{SnS}$, making $\alpha$-SnS the favorable phase in this comparison. However, the absolute values of various ligand adsorption energies on the (100) surfaces of $\pi$-SnS particles are much higher than those on any facet of $\alpha$-SnS. Under conditions of ligand termination, the overall free energy is thereby rather minimized for the $\pi$-phase, and the growth of ligandterminated $\pi$-SnS nanoparticles becomes thermodynamically favorable. Since the free energy varies so much with surface termination, the $\mathrm{SnS}$ growth mode is strongly influenced by both density and bonding characteristics of ligands adsorbed onto its surfaces. The relative contribution of surface energy increases with decreasing nanoparticle size and film thickness, emphasizing its role in the initial film growth.

Spectroscopic Ellipsometry. In general, the information on the substrate surface energy of relevance for film growth, for example, by contact angle measurements, is not straightforward to obtain due to its sensitive dependence on various conditions. Since these include temperature, ambient atmosphere, and processing history of the sample, in situ characterization at close to the growth conditions is more or less a requirement. Here, in situ spectroscopic ellipsometry (SE) is a useful optical technique for accessing the information on the substrate condition and film growth. Minute changes of surface layers, down to fractions of an Ångström in thickness, are readily detected. This permits the study of the initial film growth as well as its more long-term behavior. In this work, SE spectra were collected every few seconds, providing several sampling points per ALD cycle. To interpret the data, optical modeling was applied by means of a three-layer model for the growing SnS film: a bottom layer for material next to the substrate interface, a mid layer for $\mathrm{SnS}$ of more bulklike character, and an EMA layer for the mixed layer of SnS and vacuum resulting from surface roughness, as further described in the Materials and Methods section. The solid thickness of SnS, obtained by adding the thicknesses of these three layers after multiplying the top EMA layer thickness by its $\mathrm{SnS}$ filling factor (i.e., its solid volume fraction) is used as a measure of the total amount of $\mathrm{SnS}$ deposited on the substrate.

$\mathrm{On} \mathrm{Si}-\mathrm{OH}$ with no annealing, the $\mathrm{SnS}$ growth rate is initially higher than steady state, but it relaxes to the steady state after 50-100 ALD cycles (Figure 4a). As discussed above, growth on this type of substrate results in a high fraction of the $\alpha$-SnS phase after completion of 1000 ALD cycles. This manifests in a comparatively low GI-XRD peak fraction (inset of Figure 4b). In contrast, $\mathrm{SnS}$ growth on annealed $\mathrm{Si}-\mathrm{OH}$ substrates or on $\mathrm{Si}-\mathrm{OH}$ substrates modified by a few $\mathrm{ALD}$ cycles of $\mathrm{Al}_{2} \mathrm{O}_{3}$ displays a more complex dynamics (Figure 4a). Somewhat counterintuitively, the presumably increased surface energy and reactivity after annealing or $\mathrm{Al}_{2} \mathrm{O}_{3}$ deposition leads to a slower growth rate after the first $\mathrm{Sn}(\mathrm{acac})_{2}$-pulse. The $\mathrm{SnS}$ growth is increasingly suppressed with the number of $\mathrm{Al}_{2} \mathrm{O}_{3}$ cycles up to five. At this point, a nearly closed $\mathrm{Al}_{2} \mathrm{O}_{3}$ film presumably forms on top of $\mathrm{Si}^{34}$ and additional $\mathrm{Al}_{2} \mathrm{O}_{3}$ cycles do not make a clear difference for the $\mathrm{SnS}$ growth. After the initial inhibition, the SnS growth rate increases approximately parabolically over a long period of several hundred ALD cycles, and it exceeds the steady-state rate before leveling off to linear, steady-state growth. The GIXRD peak fraction, measured after completion of $1000 \mathrm{SnS}$ cycles, suggests an initially rapid increase of the content of the cubic $\mathrm{SnS}$ phase with the number of $\mathrm{Al}_{2} \mathrm{O}_{3}$ cycles on the substrate. This connection between the substrate properties, initial growth behavior, and the final phase composition is emphasized by an approximately logarithmic dependence of the GI-XRD peak fraction on the initial growth rate $\left(\mathrm{GR}_{\mathrm{i}}\right)$, as illustrated by Figure $4 \mathrm{~b}$. The $\mathrm{GR}_{\mathrm{i}}$ was here evaluated right after the first $\mathrm{Sn}$ (acac) $)_{2}$ pulse (that is, at 0.5 ALD cycles) by means of a second-degree polynomial fitted over the range from 0.5 to 4.5 cycles, as shown in the inset of Figure $4 \mathrm{a}$ and further discussed below. The strong relationship between the initial growth behavior and the composition of the crystal phase in the final film clearly indicates the existence of distinct growth modes, where one is connected to the development of the 

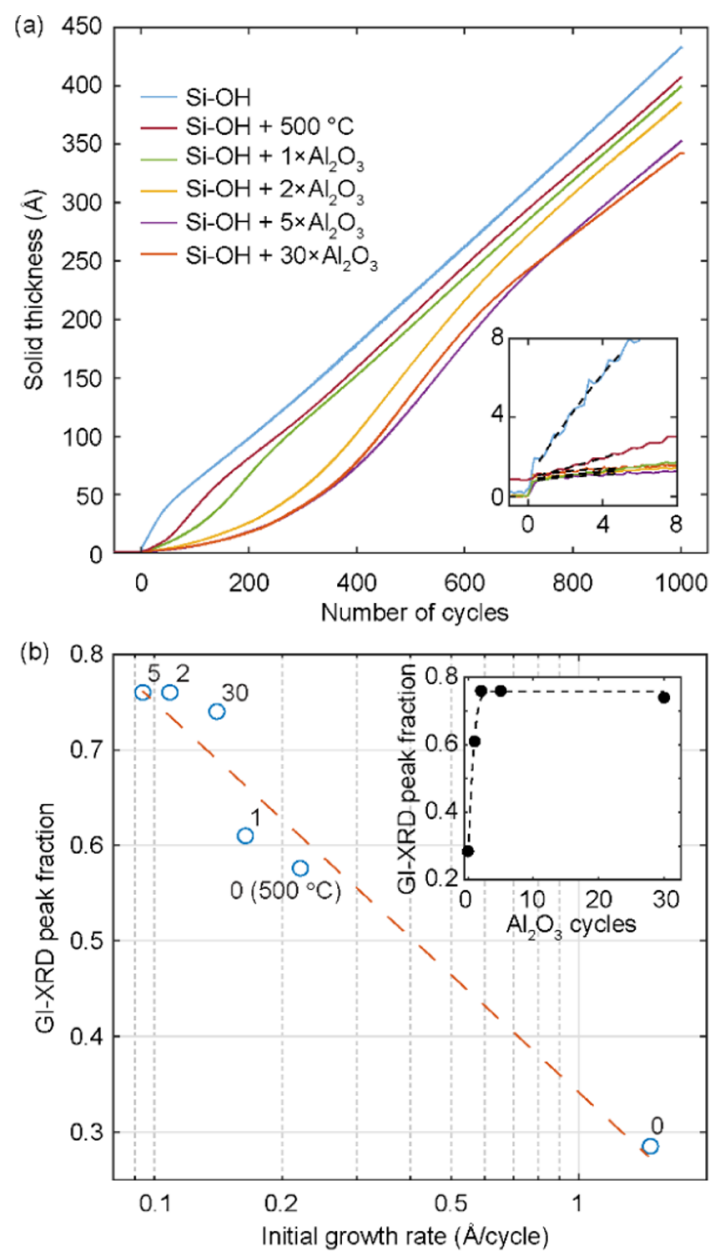

Figure 4. (a) In situ $\mathrm{SE}$ analysis of $\mathrm{SnS}$ film growth on $\mathrm{Si}-\mathrm{OH}$ substrates modified as indicated in the legend. The inset shows the fitted portions of the growth curves (dashed lines) used to determine the initial growth rate. (b) Final GI-XRD peak fraction of SnS films formed after 1000 ALD cycles versus the logarithm of the initial growth rate. The corresponding numbers of $\mathrm{Al}_{2} \mathrm{O}_{3} \mathrm{ALD}$ cycles used to modify the substrate are shown by the data labels. The inset shows the final SnS GI-XRD peak fraction versus the number of $\mathrm{Al}_{2} \mathrm{O}_{3}$ cycles $(x)$ on the $\mathrm{Si}-\mathrm{OH}$ substrate, with a fitted exponential dependence $[0.76$ $-0.63 \exp (-1.3 x)]$.

cubic and another to the orthorhombic SnS phase. For this to be possible, some critical aspect of the growth surface(s) must promote one growth mode over the other while being preserved over many repeated ALD cycles. A familiar example of this is lattice matching, ${ }^{35}$ that is, that surface facets with lattice constants matching one phase of the material may favor the growth of that phase over, for instance, an amorphous phase. In the same fashion, a substrate with a surface that matches the growth surface of one of the polymorphs in a critical sense may initiate the corresponding growth mode. Recently, a combination of lattice matching and chemical compatibility was reported to yield epitaxial $\pi$-SnS growth on $\mathrm{PbS}^{24}$ In the present case, however, such chemical epitaxy ${ }^{24}$ or more plain lattice matching is not well suited to explain the substrate dependence, as $\mathrm{Al}_{2} \mathrm{O}_{3}$ and the oxide of $\mathrm{Si}^{36}$ both have amorphous surfaces. An overlayer of hydroxyl groups is unlikely to change that. This necessitates surface chemistry alone to yield phase selectivity in the present cases.
Initial Growth. To elucidate the initial growth behavior further, we note that for films with thicknesses on the Ångström level, changes of the refractive index versus thickness are not robustly distinguished by SE in the regular optical range. For this reason, a fixed set of typical optical constants for $\mathrm{SnS}$ were deployed when measuring only the first few cycles of growth, as in Figure 5, where the initial pulses and cycles of the
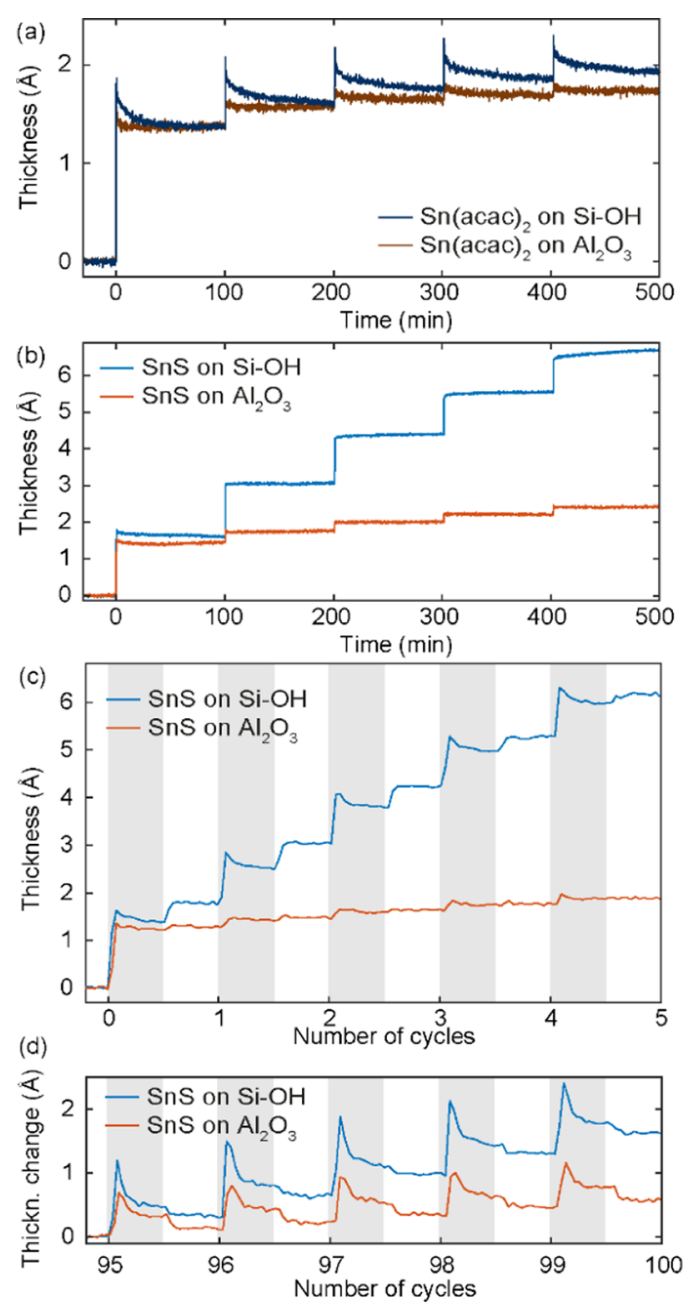

Figure 5. (a) Long-term effects of $\mathrm{Sn}(\mathrm{acac})_{2}$ pulses on $\mathrm{Si}$ and on ultrathin $\mathrm{Al}_{2} \mathrm{O}_{3}$ ( 30 cycles on $\mathrm{Si}$ ). One pulse (1.6 s long) is performed every $100 \mathrm{~min}$. (b) Long-term effects of full SnS ALD cycles $(20 \mathrm{~s}$ long) on the same substrates, performed every $100 \mathrm{~min}$. (c) Regular $\mathrm{SnS}$ ALD cycles on $\mathrm{Si}-\mathrm{OH}$ - and $\mathrm{Al}_{2} \mathrm{O}_{3}$-modified $\mathrm{Si}$ substrates at the initial stages and (d) after the first 95 cycles. Gray fields indicate the $\mathrm{Sn}(\mathrm{acac})_{2}$ half-cycles, and the white fields indicate the $\mathrm{H}_{2} \mathrm{~S}$ half-cycles.

$\mathrm{SnS}$ deposition are compared for $\mathrm{Si}-\mathrm{OH}$ - and $\mathrm{Al}_{2} \mathrm{O}_{3}$-modified $\mathrm{Si}-\mathrm{OH}$. The suppressed growth on $\mathrm{Al}_{2} \mathrm{O}_{3}$-modified $\mathrm{Si}-\mathrm{OH}$ is seen to follow immediately after the first $\mathrm{Sn}(\mathrm{acac})_{2}$ pulse and the associated step in thickness (Figure 5a). Based on the suppressed growth of $\mathrm{Pd}$ on $\mathrm{Al}_{2} \mathrm{O}_{3}$ using $\mathrm{Pd}$ (hexafluoroacetylacetone) $)_{2}$, it has previously been suggested that the acetylacetonate (acac) ligands of $\mathrm{Sn}(\mathrm{acac})_{2}$ form an $\mathrm{Al}$-acac surface species, which blocks or strongly suppresses further precursor adsorption. ${ }^{18}$ It has also been demonstrated that acac ligands derived from $\mathrm{Cr}(\mathrm{acac})_{3}$ form donoracceptor-type bonds with $\mathrm{Al}^{3+}$ ions exposed on $\mathrm{Al}_{2} \mathrm{O}_{3}$ surfaces. A strong ligand bonding can explain the slow overall $\mathrm{SnS}$ growth rate following the first ALD cycle, as observed in Figure 
5b. This is additionally supported by studying the initial cycles with individual pulses resolved during regular ALD conditions, as shown in Figure 5c. This shows that the strongly bound ligands on $\mathrm{Al}_{2} \mathrm{O}_{3}$ form a stable layer with a low reactivity toward $\mathrm{H}_{2} \mathrm{~S}$ and that these ligands thereby suppress further $\mathrm{SnS}$ growth. The surface poisoning of this ligand adsorption is less obvious on preannealed $\mathrm{Si}-\mathrm{OH}$, where a clear thickness step is missing (inset of Figure 4a). We believe this is due to evaporation of some $\mathrm{Sn}(\mathrm{acac})_{2}$ precursor from the delivery line, unintentionally heated during the annealing step. This may lead to adsorption of ligands or other species on the annealed substrates prior to the actual ALD run and thereby to the lack of a clear thickness step in this case.

In contrast to the facets of the inherently layered $\alpha$-SnS structure, Segev et al. recently demonstrated by DFT calculations that the facets of $\pi$-SnS have a relatively high density of localized surface states. ${ }^{37}$ This is a consequence of the cubic symmetry, for which crystal cleavage inevitably leads to dangling bonds of exposed Sn atoms. ${ }^{32}$ Ligand adsorption on these $\mathrm{Sn}^{2+}$ sites, where, in the present case, oxygen of the acac ligand takes the place of sulfur in the SnS structure, promotes further growth of $\pi$-SnS by stabilizing this phase through high adsorption energy. ${ }^{32}$ Strong ligand bonding is thus a key aspect for sustaining the $\pi$-SnS growth on itself, and possibly for its selective nucleation on a substrate.

Immediately after the first $\mathrm{Sn}(\mathrm{acac})_{2}$-exposure on $\mathrm{Si}-\mathrm{OH}$, we find that the layer thickness is higher than that on $\mathrm{Al}_{2} \mathrm{O}_{3}$ but transiently decreasing toward the latter (Figure 5a). A higher thickness is consistent with weaker, more extended bonds to ligands and $\mathrm{Sn}$ species formed after $\mathrm{Sn}(\mathrm{acac})_{2}$ dissociation on $\mathrm{Si}-\mathrm{OH}$ but could also be due to more extensive physisorption of the intact precursor on the $\mathrm{Si}-\mathrm{OH}$ substrate. For several metal(acac) $)_{2}$ complexes, such as $\mathrm{Cr}(\mathrm{acac})_{3}, \mathrm{Pd}(\mathrm{acac})_{2}$, and $\mathrm{Cu}(\mathrm{acac})_{2}$, adsorption on silica has been shown to occur without decomposition of the precursor, i.e., via hydrogen bonding or other unspecific interactions. ${ }^{38-41}$ On the other hand, the asymptotic approach of the layer thickness observed on $\mathrm{Al}_{2} \mathrm{O}_{3}$ after the first $\mathrm{Sn}(\mathrm{acac})_{2}$ injection on $\mathrm{Si}-\mathrm{OH}$ (Figure 5a) rather supports the eventual formation of a ligand-terminated surface on $\mathrm{Si}-\mathrm{OH}$ similar to the one on $\mathrm{Al}_{2} \mathrm{O}_{3}$. Perhaps the most likely scenario is a mixed layer of intact and dissociated $\mathrm{Sn}(\mathrm{acac})_{2}$ on $\mathrm{Si}-\mathrm{OH}$, where the transient thickness reduction signifies dissociation and formation of $\|-\mathrm{acac}$ and $\|-\mathrm{Sn}$ surface species, with the symbol || representing the substrate. As the free energy gain from this dissociation is likely small on $\alpha$-SnS (because the gain from adsorption of other types of ligands is small on its common facets ${ }^{32}$ ), the process is likely slow. It should also result in the desorption of ligands through protonation and Hacac $(\mathrm{g})$ formation on the hydroxylated surface. Thickness steps in the growth curve upon $\mathrm{H}_{2} \mathrm{~S}$ pulsing (Figure 5c) indicate that the weak $\|$-acac bonds are susceptible to attack from $\mathrm{H}_{2} \mathrm{~S}$ [for example, by formation of $\mathrm{Hacac}(\mathrm{g})$ and $\|-\mathrm{SH}$ ] and lead to the rapid initial growth observed in this case (Figure 4a). In this context, it is interesting to note that the reactivity with $\mathrm{H}_{2} \mathrm{O}$ is much lower than that with $\mathrm{H}_{2} \mathrm{~S}$, resulting in a 4-5 times slower growth rate (of presumably $\mathrm{SnO}$, not shown here) on $\mathrm{Si}-\mathrm{OH}$. Thermodynamically, the $\mathrm{H}_{2} \mathrm{O}$ dissociation energy is almost 15 times higher $(2.9 \mathrm{eV})$ than for $\mathrm{H}_{2} \mathrm{~S}(0.2 \mathrm{eV})$, ${ }^{40}$ which may essentially explain this.

The full ALD cycle on long (Figure $5 b$ ) and short (Figure 5c) timescales demonstrate a net buildup of the thickness with the first $\mathrm{H}_{2} \mathrm{~S}$ pulse, especially on $\mathrm{Si}-\mathrm{OH}$. From this observation, it appears unlikely that the majority of the surface would be occupied by physisorbed $\mathrm{Sn}(\mathrm{acac})_{2}$ after the Snprecursor pulses, as the reaction with $\mathrm{H}_{2} \mathrm{~S}$ and formation of $\mathrm{SnS}$ through the dispelling of both ligands would rather imply a reduction of the effective film thickness. It is, however, uncertain how much the ligands contribute to the optical properties in relation to $\mathrm{Sn}$ and $\mathrm{S}$, as this depends on the unknown spectral distribution of oscillator strength here. Regardless, the growth on $\mathrm{Si}-\mathrm{OH}$ and $\mathrm{Al}_{2} \mathrm{O}_{3}$ behave in a qualitatively similar way when exposed to $\mathrm{H}_{2} \mathrm{~S}$. It therefore seems feasible that $\mathrm{Sn}(\mathrm{acac})_{2}$ dissociates on both types of substrates, and that $\mathrm{H}_{2} \mathrm{~S}$ exposure leads to displacement of most ligands from $\mathrm{Si}-\mathrm{OH}$ but a relatively small fraction from $\mathrm{Al}_{2} \mathrm{O}_{3}$. Thus, the selective growth of $\alpha$ - or $\pi$-SnS primarily depends on the strength of the ligand interaction with the substrate.

Temperature and $\mathrm{H}_{2} \mathrm{~S}$ Dose Dependence. In previous work, it was found that the $\pi$-SnS growth is favored by low substrate temperatures (at least down to $80{ }^{\circ} \mathrm{C}$ ) and high $\mathrm{H}_{2} \mathrm{~S}$ doses. ${ }^{14}$ In the current context, it may seem contradictory that a high $\mathrm{H}_{2} \mathrm{~S}$ dose does not rather favor the growth of the $\alpha$-SnS polymorph since high $\mathrm{H}_{2} \mathrm{~S}$ exposure should result in more ligand exchange and thereby drive the surface toward the bare, nonterminated condition. On the other hand, one may wonder how the growth of the $\pi$-SnS polymorph can occur at all, if termination and "surface poisoning" by acac ligands is a prerequisite for its stability. Perhaps the answer to these conundrums lies in a relatively delicate balance of processes, which is easily influenced by several factors.

If considering first the growth of $\pi$-SnS on itself, it is clear that the phase-stabilizing ligands must, somehow, be exchanged with sulfur from $\mathrm{H}_{2} \mathrm{~S}$. If the ligands are completely removed, the bare $\pi$-SnS surface that forms has at least three times higher surface energy than the lowest energy facets of the $\alpha$-SnS polymorph. ${ }^{32}$ Even a partial removal can thus be enough for thermodynamics to favor a (surface or crystal) reorganization toward the more stable $\alpha$-SnS polymorph. A higher temperature will help overcome any barriers to such reconstruction and thereby promote the growth of the $\alpha$-SnS polymorph. Conversely, a low temperature could permit the $\pi$ $\mathrm{SnS}$ polymorph and its higher density of $\mathrm{Sn}$ dangling bonds to be preserved until the ligand termination is replenished during the next ALD cycle. Hence, when ligand exchange with sulfur is prevalent, the temperature dependence can be explained.

Regarding the $\mathrm{H}_{2} \mathrm{~S}$ dose dependence, the exchange of the stabilizing ligands with sulfur is an energetically less favorable process on the $\pi$-SnS surface than that on the $\alpha$-SnS surface. The ligand exchange reaction may therefore require a higher $\mathrm{H}_{2} \mathrm{~S}$ dose to complete on the $\pi$-SnS surface. A high $\mathrm{H}_{2} \mathrm{~S}$ partial pressure could, especially in combination with the continuous removal of desorbed products through pumping, produce a temporary chemical potential able to quickly drive most acac ligands off the surface. With a relatively low $\mathrm{H}_{2} \mathrm{~S}$ dose, on the other hand, the faster exchange on $\alpha$-SnS facets will promote the growth of the $\alpha$-SnS polymorph over $\pi$-SnS when they coexist on the surface. One implication of this is that high $\mathrm{H}_{2} \mathrm{~S}$ doses should result in similar steady-state growth rates of $\pi$ $\mathrm{SnS}$ and $\alpha$-SnS [that is, provided the ligand coverage after $\mathrm{Sn}(\mathrm{acac})_{2}$ exposure is similar on $\alpha$-SnS and $\pi$-SnS]. This is more or less confirmed in Figure 4a. Further support for nearcomplete ligand removal on both $\pi$ - and $\alpha$-SnS is found from the qualitatively similar $\pi$-SnS and $\alpha$-SnS growth behavior after a relatively short induction period, see Figure $5 \mathrm{~d}$. Thus, the 
chemical potential variation with the $\mathrm{H}_{2} \mathrm{~S}$ dose may explain the previously observed ${ }^{14} \mathrm{H}_{2} \mathrm{~S}$ dose dependence. These observations also corroborate a quantitative rather than qualitative difference in the governing surface chemistry of the two growth modes.

The emerging picture is thus that $\mathrm{SnS}$ surfaces are terminated by acac ligands after $\mathrm{Sn}(\mathrm{acac})_{2}$ exposure. This stabilizes $\pi$-SnS growth, but with sufficiently high $\mathrm{H}_{2} \mathrm{~S}$ concentration, more or less all of the adsorbed ligands are exchanged during the subsequent $\mathrm{H}_{2} \mathrm{~S}$ pulse. The growth of $\alpha$ $\mathrm{SnS}$ benefits from a faster exchange of more loosely bound ligands on $\alpha$-SnS facets and by reconstruction of $\pi$-SnS into $\alpha$ $\mathrm{SnS}$ at high temperatures. This allows the previously observed temperature and $\mathrm{H}_{2} \mathrm{~S}$ dose dependences to be explained.

Substrate Effects. When it comes to the influence of the substrate, it appears that $\mathrm{Al}_{2} \mathrm{O}_{3}$-modified and $\mathrm{Si}-\mathrm{OH}$ substrates are similarly terminated by ligands after the first $\mathrm{Sn}(\mathrm{acac})_{2}$ exposure (Figure 5a). Depending on the substrate, strongly bound ligands lead to surface poisoning, sparse nucleation, and slow growth of the $\pi$-SnS phase, whereas loosely bond ligands promote rapid growth of the $\alpha$-SnS phase. A critical question here is how the chemical interactions with the substrate surface translate to a preference for one $\mathrm{SnS}$ phase over the other. Two basic possibilities are that (i) initial growth on a surface covered by strongly bound ligands requires strong interaction with the ligands, i.e., the type of interaction found only with the dangling bonds of the $\pi$-SnS phase, and (ii) dense nucleation on surfaces with loosely bound ligands leads to steric effects in favor of the $\alpha$-SnS phase. The former scenario is a more direct translation of surface chemistry to the crystal structure and assumes little in addition to the requirements for $\pi$-SnS growth on itself. The latter, on the other hand, readily aligns with the different growth behaviors associated with the development of $\pi$ - and $\alpha$-SnS.

The $\alpha$-SnS growth mode is a form of substrate-enhanced growth, which typically occurs when the density of adsorption sites on the substrate exceeds the density of adsorption sites on the surface of the grown film. Dense nucleation is thus supported in this case, and initial layer-by-layer-type growth is feasible. A naturally layered phase, such as $\alpha$-SnS, may then be energetically favored. Relaxation to linear, steady-state growth follows after full coverage is achieved and the influence of the substrate has subsided. This occurs in the range of 50-100 cycles (Figure 4a) here, which is typically more than what is needed for film closure-especially in the case of layer-by-layer growth. For this reason, a layer-plus-island (StranskiKrastanov) type of growth appears more likely. This would also help explain the high roughness observed for $\alpha$-SnS-rich films (Figure 1a), which would not be produced by pure layerby-layer growth.

The growth behavior on $\mathrm{Al}_{2} \mathrm{O}_{3}$-modified $\mathrm{Si}-\mathrm{OH}$, on the other hand, is after the first $\mathrm{Sn}(\mathrm{acac})_{2}$ pulse rather characterized as a substrate-inhibited growth of type 2, which is frequently associated with island (Volmer-Weber)-type growth. The growth curve displays a transition regime between initial growth and steady-state growth, where the growth rate is temporarily enhanced, as seen between 400 and 600 cycles here (Figure 4a). This can be understood since the surface area of an island expands in three dimensions and exceeds the area it occupies on the substrate, for example, by a factor 2 in the case of a hemispherical shape. The total surface area will peak just prior to island coalescence, resulting in a peak overall growth rate (in terms of solid thickness) since the growth is faster on island surfaces compared to that on the substrate. ${ }^{42,43}$ Alternatively, activation and growth promotion in a strip on the substrate near the perimeter of growing islands could produce an enhanced growth rate that peaks slightly before island coalescence. In either case, the three-dimensional and more isotropic island-type growth should favor the isotropic $\pi$ $\mathrm{SnS}$ crystal structure from symmetry considerations. The phase development may thus be the result of a combination of surface interactions (weak versus strong ligand bonding) and steric/symmetry effects, producing initially layered versus island-type growth.

Additional experimental work, preferably supported by DFT calculations, would be required to develop a more detailed mechanistic understanding here.

Generalization to Other Substrates. As a contrasting example to $\mathrm{Al}_{2} \mathrm{O}_{3}$-modified $\mathrm{Si}-\mathrm{OH}, \mathrm{SnS}$ grows preferentially in the $\pi$-SnS polymorph on the native oxide of a sputtered, $80 \mathrm{~nm}$ thick Ti layer on Si. Modification of this surface by $\mathrm{ZnS}$ ALD promotes the $\alpha$-SnS polymorph, as demonstrated in the inset of Figure 6, where the final GI-XRD peak fractions of $\mathrm{SnS}$ films

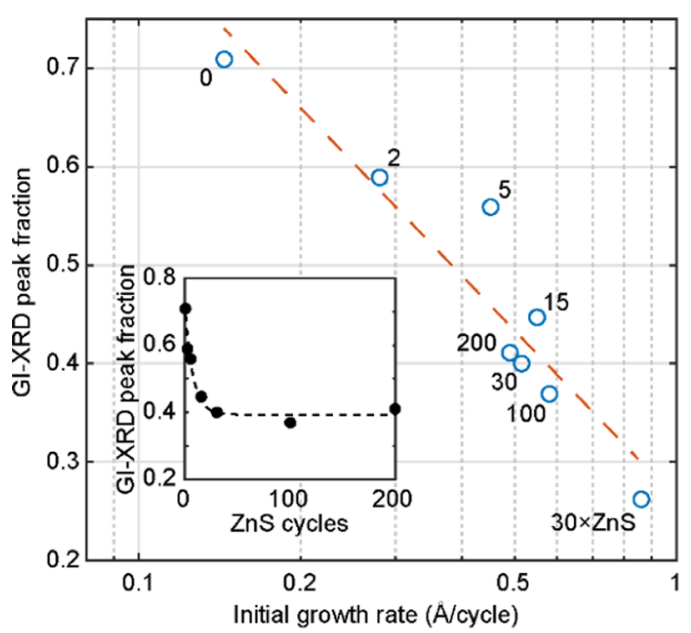

Figure 6. Relationship between the initial growth rate, extracted by in situ SE, and the final GI-XRD peak fraction of SnS films grown on a Ti substrate after modification by the indicated number of ZnS ALD cycles. The data for 30 cycles of $\mathrm{ZnS}$ on $\mathrm{Si}-\mathrm{OH}$ is also included and indicated as $30 \times \mathrm{ZnS}$. The inset shows the GI-XRD peak fraction versus the number of $\mathrm{ZnS}$ cycles $(x)$ on $\mathrm{Ti}$, with a fitted exponential dependence $[0.39+0.75 \exp (-0.13 x)]$.

are shown versus the number of $\mathrm{ZnS}$ ALD cycles. It takes approximately 30 cycles to fully develop the effect of $\mathrm{ZnS}$ ALD on the Ti surface.

An exponential decay function fitted to the GI-XRD peak fraction gives a rate constant for its change of $0.13 / \mathrm{ZnS}$ cycle, which is ten times slower than for modification by $\mathrm{Al}_{2} \mathrm{O}_{3} \mathrm{ALD}$ on $\mathrm{Si}-\mathrm{OH}$. When studying the logarithm of the initial $\mathrm{SnS}$ growth rates from in situ SE, a quite strong correlation $\left(R^{2}=\right.$ 0.89 ) with the final GI-XRD fraction is observed for $\mathrm{ZnS}$ modified Ti substrates, as illustrated in Figure 6. In this graph, $\mathrm{SnS}$ grown on $\mathrm{Si}-\mathrm{OH}$ modified by 30 ALD cycles of $\mathrm{ZnS}$ is also included, showing one of the purest orthorhombic films measured in this work. The difference between the effect of $\mathrm{ZnS}$ on $\mathrm{Ti}$ and $\mathrm{Si}-\mathrm{OH}$ may be attributed to substrate roughness. It has previously been shown that $\mathrm{ZnS}$ grown by $\mathrm{ALD}$ has a pronounced island-type growth on $\mathrm{SiO}_{2}$. Although $\mathrm{ZnS}$ islands coalesce on $\mathrm{SiO}_{2}$ already after a few ALD cycles, 

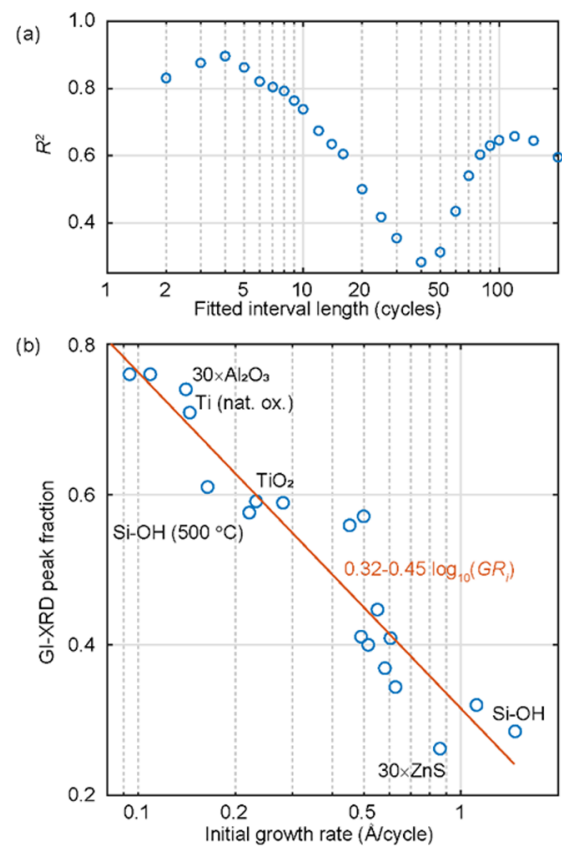

(c)

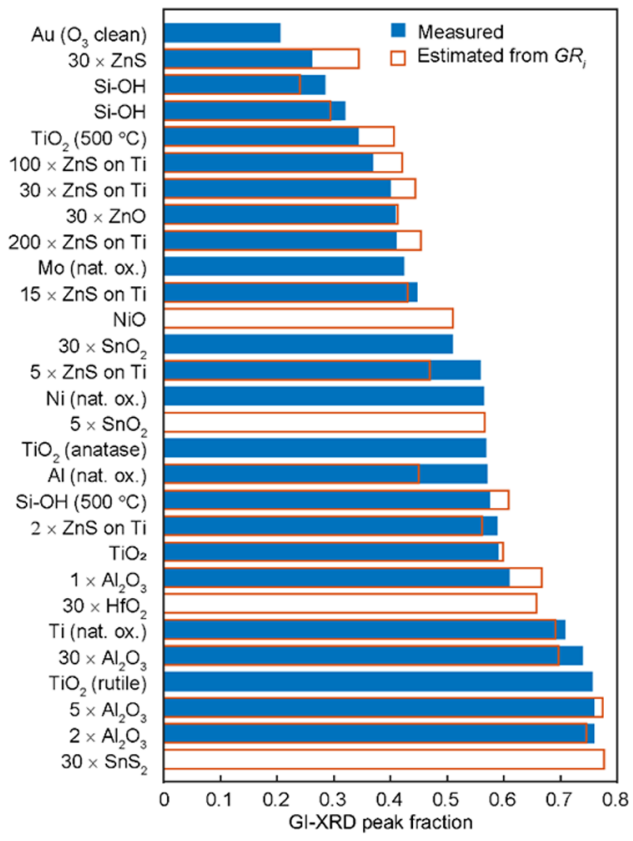

Figure 7. (a) Coefficient of determination $\left(R^{2}\right)$ for GI-XRD peak fraction predicted by the logarithmized initial growth rate versus the number of ALD cycles used in the growth rate estimation. (b) GI-XRD peak fraction versus initial growth rate on various substrates, extracted for fits over four ALD cycles $\left(R^{2}=90 \%\right)$. (c) Measured and estimated GI-XRD peak fractions for SnS films grown on various substrates. The estimates are based on the linear interpolation shown in $(b)$.

the higher roughness of the sputtered Ti surface may delay this and also accentuate the $\mathrm{ZnS}$ surface roughness beyond the point of film closure.

Then, the initial layer-by-layer growth that we have associated with $\alpha$-SnS is less favored after $30 \mathrm{ZnS}$ cycles on $\mathrm{Ti}$ than after $30 \mathrm{ZnS}$ cycles on $\mathrm{Si}-\mathrm{OH}$.

More generally, the $\mathrm{SnS}$ growth depends in a delicate manner on the substrate surface condition. Even on the $\mathrm{SnS}$ surfaces themselves, our results imply that the differences between the facets of its two polymorphs result in selective $\pi$ SnS growth on $\pi$-SnS and selective $\alpha$-SnS growth on $\alpha$-SnS. Due to this sensitivity, predictions for other substrate surfaces are not straightforward. Substrate characteristics that may influence the SnS growth include both the density and reactivity of dangling bonds and other reactive surface sites, such as lattice defects of surface species, such as $\mathrm{OH}$ groups, and of various forms of surface contamination. In this context, the initial growth rate extracted by in situ SE can be a useful proxy for the surface properties of importance. To further investigate this, we studied the behavior and resulting GI-XRD peak fractions on various substrate surfaces.

As in previous examples, $\mathrm{GR}_{\mathrm{i}}$ was extracted from the derivative of a second-degree polynomial fitted to the growth curve. Since similar thickness steps are typically observed during the first $\mathrm{Sn}(\mathrm{acac})_{2}$ pulse, the lower limit of the fitted range was set to 0.5 ALD cycles, that is, right after the first $\mathrm{Sn}(\mathrm{acac})_{2}$ pulse and purge sequence. This is also the point where $G_{i}$ was evaluated. When varying the range fitted by the polynomial for measurements on several different types of substrates (see Figure 7), the correlation of $\log \left(\mathrm{GR}_{\mathrm{i}}\right)$ with the GI-XRD data peaks at $95 \%\left(R^{2}=0.90\right)$ for a relatively short interval of four ALD cycles (Figure 7a). For shorter ranges, the correlation declines due to limited time resolution and noise in the measurements, while longer ranges weaken the relationship due to larger fitting errors for some of the growth curves.
Weaker correlation is found with other growth characteristics, such as the steady-state growth rate (extracted near the end of the $\mathrm{SnS}$ deposition), the final film thickness, the nucleation delay (by linear extrapolation of steady-state growth to the abscissa), and the plain $\mathrm{GR}_{\mathrm{i}}$. The final film thickness comes closest to $\log \left(\mathrm{GR}_{\mathrm{i}}\right)$ in explanatory power for the final $\mathrm{SnS}$ phase, with $R^{2}=0.60$. A comparison of the measured and estimated GI-XRD peak fractions for various substrates is provided in Figure $7 c$, where some estimates based only on the relationship to $\log _{10}\left(\mathrm{GR}_{\mathrm{i}}\right)$ shown in Figure $7 \mathrm{~b}$ are also included. More details on the substrate preparations are given in the Supporting Information, Table S1.

There are cases where predictions based on the initial growth rate will arguably fail. This includes situations where the substrate surface layer is unstable or etched by either ALD precursor, as this will interfere with both actual film growth and the ellipsometric analysis of it. In other instances, the initial growth is so strongly suppressed that meaningful GIXRD data is hard to obtain. For SnS grown on 30 cycles of tin disulfide (near-stoichiometric $\mathrm{SnS}_{2}$ ), produced by ALD using TDMASn(IV) and $\mathrm{H}_{2} \mathrm{~S},{ }^{20,44}$ a solid thickness of less than $7 \mathrm{~nm}$ is observed after $1000 \mathrm{SnS}$ cycles, see Figure 8a. The exceptionally low initial growth rate predicts a predominantly $\pi$-SnS film (Figure 7c). This is further corroborated by the qualitatively similar behavior to growth on $\mathrm{Al}_{2} \mathrm{O}_{3}$, although it is more extreme on $\mathrm{SnS}_{2}$. Just like $\mathrm{Al}_{2} \mathrm{O}_{3}, \mathrm{SnS}_{2}$, grown at $120{ }^{\circ} \mathrm{C}$ with TDMASn, is highly amorphous ${ }^{20,44}$ and may therefore expose a high density of dangling bonds. However, the GIXRD measurement for $\mathrm{SnS}$ on $\mathrm{SnS}_{2}$ cannot be used to confirm the $\mathrm{SnS}$ phase, as only a single, weak peak is observed at approximately $2 \theta=31.8^{\circ}$ (Figure 9a). Further, the Raman spectrum is flat except for a peak slightly above $300 \mathrm{~cm}^{-1}$. The latter is likely related to the amorphous $\mathrm{SnS}_{2}$ film on the $\mathrm{Si}$ substrate (Figure 9b) since the $\mathrm{A}_{1 \mathrm{~g}}$ peak of crystalline $\mathrm{SnS}_{2}$ is found in this region. ${ }^{45}$ It is therefore unclear which $\mathrm{SnS}$ 


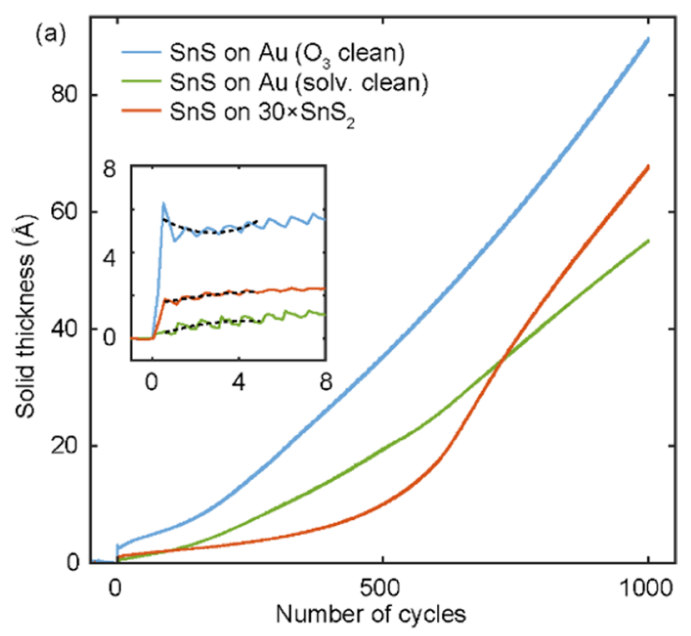

(b)

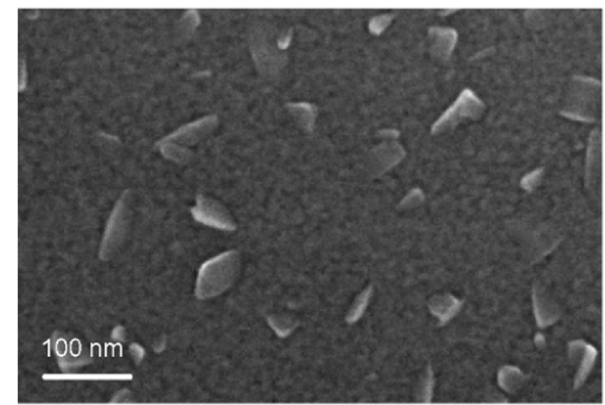

(c)

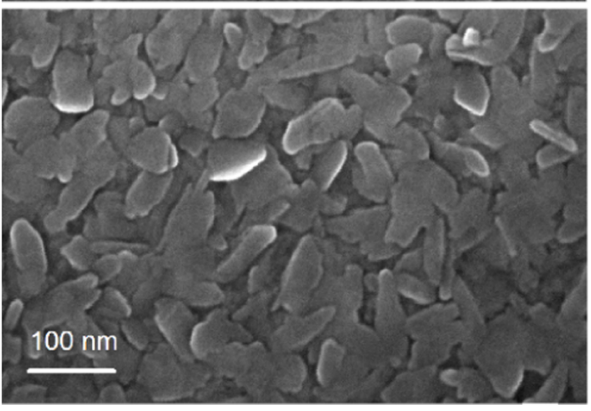

Figure 8. (a) SnS growth during ALD on Au substrates, cleaned either in situ by $\mathrm{O}_{3}$ or ex situ by a solvent. Growth on $\mathrm{SnS}_{2}$ is also shown. (b) SEM after $1000 \mathrm{SnS}$ cycles on $\mathrm{SnS}_{2}$ suggests nucleation is strongly suppressed on this surface. (c) SEM after $1000 \mathrm{SnS}$ cycles on $\mathrm{Au}$ (cleaned ex situ) displays an uncharacteristic $\mathrm{SnS}$ morphology with large flakes oriented parallel to the surface plane.

polymorph eventually develops on $\mathrm{SnS}_{2}$, but SEM indicates slow formation of isolated, flat grains of seemingly crystalline nature (Figure $8 \mathrm{~b}$ ). It is worth noting that with further optimization of the $\mathrm{SnS}_{2}$ deposition process and surface patterning, the strongly suppressed growth could be of interest for area-selective ALD of SnS.

Growth on gold substrates is also interesting and of importance for applications in, for instance, plasmonics. ${ }^{9}$ The growth behavior does not fit well into any of the two main patterns discussed so far. The $\mathrm{SnS} A L D$ is initially slow (Figure 8 a) but does not accelerate as much as on $\mathrm{Al}_{2} \mathrm{O}_{3}$ and $\mathrm{SnS}_{2}$ and hence lacks a clear signature of island-type growth. The thickness step usually observed with the first $\mathrm{Sn}(\mathrm{acac})_{2}$ pulse is further obscured or missing for Au substrates exposed to air, even when acetone and isopropanol cleaning is performed shortly before loading into the reactor. The ellipsometric model also requires the bare $\mathrm{Au}$ surface to be complemented with a surface layer for adequacy. After in situ cleaning by ozone $\left(1 \mathrm{~h}\right.$, about $10 \%$ ozone in $\mathrm{O}_{2} / \mathrm{N}_{2}$ mixture at 700 SCCM flow rate), on the other hand, a large initial step is observed upon the first pulse of $\mathrm{Sn}(\mathrm{acac})_{2}$, followed by a rapid transient reminiscent of the thickness decline observed on $\mathrm{Si}-\mathrm{OH}$. This corresponds to a low but net negative initial growth rate as defined above and cannot be used for the prediction of the $\mathrm{SnS}$ phase. SEM of the resulting SnS films displays an unusual morphology with large, flat grains oriented parallel to the substrate (Figure 8c).

The results of GI-XRD are sensitive to the preparation of the Au surface but indicate a highly orthorhombic $\mathrm{SnS}$ film for the in situ ozone-treated layer with a peak fraction of 0.21 . On the other hand, the apparently textured structure of the SnS layer may affect the peak ratio and therefore be misleading with regards to the phase content of the SnS film. Meanwhile, the Raman spectra in Figure $9 \mathrm{~b}$ are less sensitive to effects of texture and agree well with the previous results for $\alpha$-SnS films. Taken together, these results are therefore most consistent with the growth of an orthorhombic polymorph in a layer-bylayer mode, with surface planes oriented more or less parallel to the $\mathrm{Au}$ surface.

More generally, we may conclude that the relationship between the logarithmized $\mathrm{GR}_{\mathrm{i}}$ and the GI-XRD peak fraction of the final SnS films holds up well-at least-for growth on oxides (including native oxides on metals and $\mathrm{Si}$ ), sulfides, and $\mathrm{Si}$ with varying degrees of hydroxylation. The previously observed relationship between the peak fraction and the SnS polymorph $^{14}$ is here additionally supported by the Raman spectra for $\mathrm{SnS}$ films grown on $\mathrm{Ti}, \mathrm{Ni}$, Mo, and $\mathrm{Au}$ (Figure 9b), which imply increasing $\alpha$-SnS content consistent with that deduced from the GI-XRD data (Figure $7 b$ ).

\section{CONCLUSIONS}

In the atomic layer deposition of tin monosulfide, the substrate can play a decisive role in the phase evolution of the grown film. This phase selectivity does not depend on lattice matching but is a chemically induced structural effect by the substrate, leading to a predominance of either the $\pi$-SnS or $\alpha$ $\mathrm{SnS}$ polymorph. On substrates with high surface energy and affinity for strong bonding with the acac ligands of the tin precursor, chemisorbed ligands cover the surface after the first tin precursor pulse and show low reactivity with $\mathrm{H}_{2} \mathrm{~S}$ in the subsequent half-cycle. This leads to a strongly suppressed growth rate and sparse nucleation of $\mathrm{SnS}$ in the initial stage of ALD. The subsequent accelerating growth rate is consistent with Volmer-Weber, island-type growth. After 1000 ALD cycles, the resulting $\mathrm{SnS}$ films have a high content of $\pi$-SnS. Conversely, on highly hydroxylated substrates or substrates with relatively weak ligand adsorption, the growth is initially enhanced and results in $\mathrm{SnS}$ films with a high content of $\alpha$-SnS.

The recent observation that growth of $\pi$-SnS in solution is stabilized by strongly bound ligands, due to passivation of the high density of dangling bonds found on the $\pi$-SnS surface planes, ${ }^{24}$ can be associated with the substrate selectivity observed here. Growth of the $\mathrm{SnS}$ polymorph that is most similar to the substrate in terms of surface-ligand bonding characteristics is promoted. Consistent with the role of the ligands, we can also explain the previously observed temperature and $\mathrm{H}_{2} \mathrm{~S}$ dose dependences if noting that the $\alpha$-SnS growth benefits from a faster exchange of more loosely bound ligands on $\alpha$-SnS facets and that reconstruction of bare, nonterminated $\pi$-SnS facets or grains into $\alpha-\operatorname{SnS}$ is feasible at elevated temperatures. 

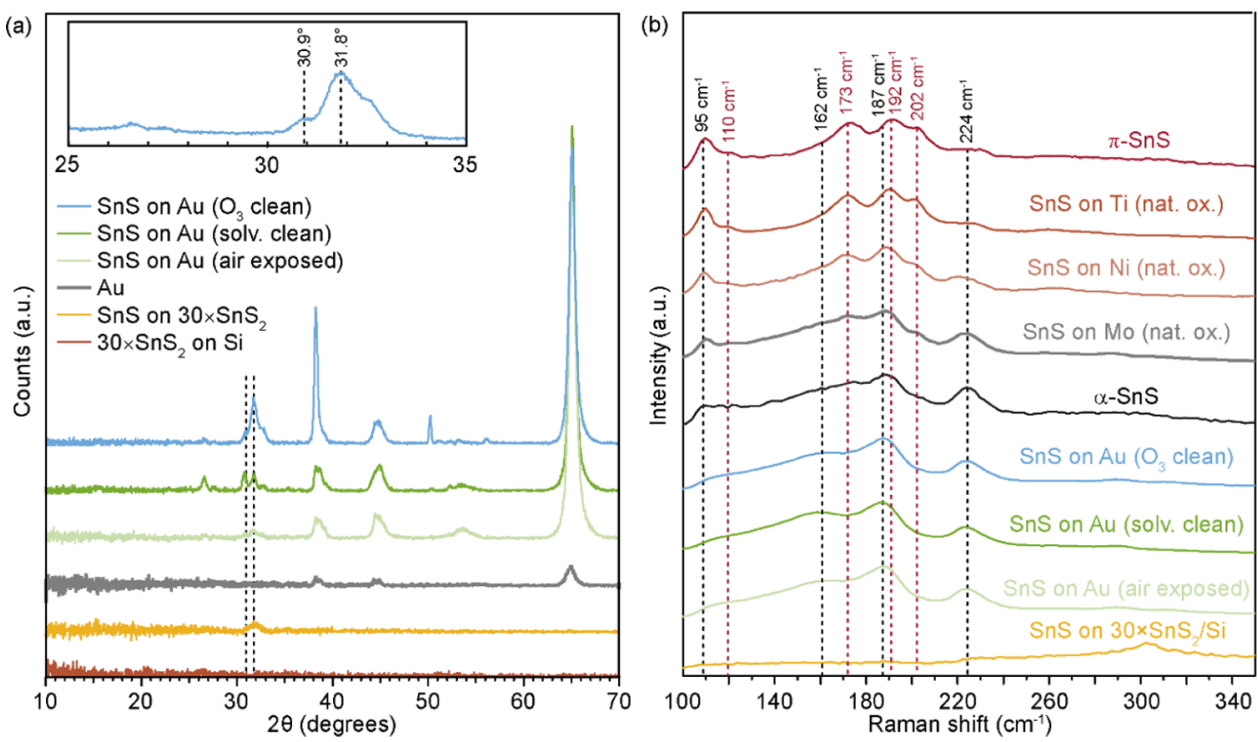

Figure 9. (a) GI-XRD for $\mathrm{SnS}$ grown on different Au substrates and on $\mathrm{SnS}_{2}$. Reference diffractograms for bare Au and the bare $\mathrm{SnS}_{2}$ film are also included. The inset is a higher-resolution scan of the $\mathrm{SnS}$ peaks used to estimate the phase fraction on $\mathrm{O}_{3}$-cleaned Au. (b) Raman spectra of SnS films (1000 ALD cycles) on various substrates, together with highly cubic and orthorhombic films obtained previously. ${ }^{14}$

Due to its sensitive dependence on substrate surface properties, the resulting $\mathrm{SnS}$ phase fraction in a film is challenging to predict. A strong connection between the logarithmized initial growth rate and the final $\mathrm{SnS}$ phase composition is nevertheless found and permits predictions based on the growth behavior of the first few ALD cycles.

The results are important for potential applications of $\mathrm{SnS}$, with implications for both growth reproducibility and $\mathrm{SnS}$ phase evolution. We show that substrate modification for control of the resulting SnS film can readily be achieved by just a few ALD cycles of a suitable material. For instance, two ALD cycles of $\mathrm{Al}_{2} \mathrm{O}_{3}$ are enough to change the growth from predominantly $\alpha$-SnS on hydroxylated Si to mainly $\pi$-SnS. The $\pi$-SnS preferentially grown on a native $\mathrm{Ti}$ oxide is conversely altered to predominantly $\alpha$-SnS through substrate modification by $30 \mathrm{ALD}$ cycles of $\mathrm{ZnS}$. The strongly suppressed growth observed on amorphous, near-stoichiometric $\mathrm{SnS}_{2}$ and to some extent gold surfaces could further be of interest for areaselective ALD of $\mathrm{SnS}$ on patterned substrates and is in the case of gold an important consideration for plasmonic applications.

\section{ASSOCIATED CONTENT}

\section{SI Supporting Information}

The Supporting Information is available free of charge at https://pubs.acs.org/doi/10.1021/acs.chemmater.1c00241.

Example of the layered model used in the ellipsometric data analysis and details on the preparation of various substrates (PDF)

\section{AUTHOR INFORMATION}

\section{Corresponding Author}

Carl Hägglund - Division of Solar Cell Technology, Department of Materials Science and Engineering, Uppsala University, 75103 Uppsala, Sweden; $\odot$ orcid.org/00000001-6589-3514; Email: carl.hagglund@angstrom.uu.se

\section{Authors}

Oleksandr V. Bilousov - Division of Solar Cell Technology, Department of Materials Science and Engineering, Uppsala University, 75103 Uppsala, Sweden

Andrii Voznyi - Division of Solar Cell Technology, Department of Materials Science and Engineering, Uppsala University, 75103 Uppsala, Sweden; Faculty of Electronics and Informational Technologies, Sumy State University, 40007 Sumy, Ukraine

Björn Landeke-Wilsmark - Division of Solar Cell Technology, Department of Materials Science and Engineering, Uppsala University, 75103 Uppsala, Sweden

Michelle Marie S. Villamayor - Division of Solid State Electronics, Department of Electrical Engineering, Uppsala University, 75103 Uppsala, Sweden

Tomas Nyberg - Division of Solid State Electronics, Department of Electrical Engineering, Uppsala University, 75103 Uppsala, Sweden

Complete contact information is available at:

https://pubs.acs.org/10.1021/acs.chemmater.1c00241

\section{Notes}

The authors declare no competing financial interest.

\section{ACKNOWLEDGMENTS}

We are very grateful to Tomas Kubart for help with substrate preparation and Myfab Uppsala for technical support and access to the cleanroom facilities. This work was supported by the Swedish Research Council, registration number 621-20145599, and the Swedish Energy Agency, project number 454091. A.V. is grateful to the Swedish Institute for a guest $\mathrm{PhD}$ scholarship. M.M.S.V. and T.N. acknowledge support from the FLAG-ERA grant LaMeS by the Swedish Research Council VR Grant 2017-06816.

\section{REFERENCES}

(1) Noguchi, H.; Setiyadi, A.; Tanamura, H.; Nagatomo, T.; Omoto, O. Characterization of vacuum-evaporated tin sulfide film for solar cell materials. Sol. Energy Mater. Sol. Cells 1994, 35, 325-331. 
(2) Abdelrahman, A. E.; Yunus, W. M. M.; Arof, A. K. Optical properties of tin sulphide $(\mathrm{SnS})$ thin film estimated from transmission spectra. J. Non-Cryst. Solids 2012, 358, 1447-1451.

(3) Sinsermsuksakul, P.; Heo, J.; Noh, W.; Hock, A. S.; Gordon, R. G. Atomic layer deposition of tin monosulfide thin films. Adv. Energy Mater. 2011, 1, 1116-1125.

(4) Rodin, A. S.; Gomes, L. C.; Carvalho, A.; Castro Neto, A. H. Valley physics in tin (II) sulfide. Phys. Rev. B: Condens. Matter Mater. Phys. 2016, 93, No. 045431.

(5) Zhang, Y.; Lu, J.; Shen, S.; Xu, H.; Wang, Q. Ultralarge single crystal SnS rectangular nanosheets. Chem. Commun. 2011, 47, 52265228.

(6) Deng, Z.; Cao, D.; He, J.; Lin, S.; Lindsay, S. M.; Liu, Y. Solution Synthesis of Ultrathin Single-Crystalline SnS Nanoribbons for Photodetectors via Phase Transition and Surface Processing. ACS Nano 2012, 6, 6197-6207.

(7) Sucharitakul, S.; Rajesh Kumar, U.; Sankar, R.; Chou, F.-C.; Chen, Y.-T.; Wang, C.; He, C.; He, R.; Gao, X. P. A. Screening limited switching performance of multilayer $2 \mathrm{D}$ semiconductor FETs: the case for SnS. Nanoscale 2016, 8, 19050-19057.

(8) Chao, J.; Wang, Z.; Xu, X.; Xiang, Q.; Song, W.; Chen, G.; Hu, J.; Chen, D. Tin sulfide nanoribbons as high performance photoelectrochemical cells, flexible photodetectors and visible-light-driven photocatalysts. RSC Adv. 2013, 3, 2746-2753.

(9) Hägglund, C.; Zeltzer, G.; Ruiz, R.; Wangperawong, A.; Roelofs, K. E.; Bent, S. F. Strong coupling of plasmon and nanocavity modes for dual-band, near-perfect absorbers and ultrathin photovoltaics. ACS Photonics 2016, 3, 456-463.

(10) Stevanović, V.; Hartman, K.; Jaramillo, R.; Ramanathan, S.; Buonassisi, T.; Graf, P. Variations of ionization potential and electron affinity as a function of surface orientation: The case of orthorhombic SnS. Appl. Phys. Lett. 2014, 104, No. 211603.

(11) Nair, P. K.; Garcia-Angelmo, A. R.; Nair, M. T. S. Cubic and orthorhombic SnS thin-film absorbers for tin sulfide solar cells. Phys. Status Solidi A 2016, 213, 170-177.

(12) Rabkin, A.; Samuha, S.; Abutbul, R. E.; Ezersky, V.; Meshi, L.; Golan, Y. New Nanocrystalline Materials: A Previously Unknown Simple Cubic Phase in the SnS Binary System. Nano Lett. 2015, 15, 2174-2179.

(13) Ahmet, I. Y.; Hill, M. S.; Johnson, A. L.; Peter, L. M. Polymorph-Selective Deposition of High Purity SnS Thin Films from a Single Source Precursor. Chem. Mater. 2015, 27, 7680-7688.

(14) Bilousov, O.; Ren, Y.; Törndahl, T.; Donzel-Gargand, O.; Ericson, T.; Platzer-Björkman, C.; Edoff, M.; Hägglund, C. Atomic layer deposition of cubic and orthorhombic phase tin monosulfide. Chem. Mater. 2017, 29, 2969-2978.

(15) Skelton, J. M.; Burton, L. A.; Oba, F.; Walsh, A. Metastable cubic tin sulfide: A novel phonon-stable chiral semiconductor. APL Mater. 2017, 5, No. 036101.

(16) Johnson, R. W.; Hultqvist, A.; Bent, S. F. A brief review of atomic layer deposition: from fundamentals to applications. Mater. Today 2014, 17, 236-246.

(17) Knoops, H. C. M.; Potts, S. E.; Bol, A. A.; Kessels, W. M. M. 27 - Atomic Layer Deposition. In Handbook of Crystal Growth, 2nd ed.; Kuech, T. F., Ed.; North-Holland: Boston, 2015; pp 1101-1134.

(18) Kim, J. Y.; George, S. M. Tin monosulfide thin films grown by atomic layer deposition using tin 2,4-pentanedionate and hydrogen sulfide. J. Phys. Chem. C 2010, 114, 17597-17603.

(19) Baek, I.-H.; Pyeon, J. J.; Song, Y. G.; Chung, T.-M.; Kim, H.-R.; Baek, S.-H.; Kim, J.-S.; Kang, C.-Y.; Choi, J.-W.; Hwang, C. S.; Han, J. H.; Kim, S. K. Synthesis of SnS Thin Films by Atomic Layer Deposition at Low Temperatures. Chem. Mater. 2017, 29, 81008110.

(20) Ham, G.; Shin, S.; Park, J.; Choi, H.; Kim, J.; Lee, Y.-A.; Seo, H.; Jeon, H. Tuning the Electronic Structure of Tin Sulfides Grown by Atomic Layer Deposition. ACS Appl. Mater. Interfaces 2013, 5, 8889-8896.

(21) Polizzotti, A.; Faghaninia, A.; Poindexter, J. R.; Nienhaus, L.; Steinmann, V.; Hoye, R. L. Z.; Felten, A.; Deyine, A.; Mangan, N. M.;
Correa-Baena, J. P.; Shin, S. S.; Jaffer, S.; Bawendi, M. G.; Lo, C.; Buonassisi, T. Improving the Carrier Lifetime of Tin Sulfide via Prediction and Mitigation of Harmful Point Defects. J. Phys. Chem. Lett. 2017, 8, 3661-3667.

(22) Wangperawong, A.; Herron, S. M.; Runser, R. R.; Hagglund, C.; Tanskanen, J. T.; Lee, H.-B.-R.; Clemens, B. M.; Bent, S. F. Vapor transport deposition and epitaxy of orthorhombic SnS on glass and $\mathrm{NaCl}$ substrates. Appl. Phys. Lett. 2013, 103 (5), 052105.

(23) Ahmet, I. Y.; Guc, M.; Sánchez, Y.; Neuschitzer, M.; IzquierdoRoca, V.; Saucedo, E.; Johnson, A. L. Evaluation of AA-CVD deposited phase pure polymorphs of SnS for thin films solar cells. RSC Adv. 2019, 9, 14899-14909.

(24) Abutbul, R. E.; Golan, Y. Chemical epitaxy of $\pi$-phase cubic tin monosulphide. CrystEngComm 2020, 22, 6170-6181.

(25) Kobayashi, H.; Jiro, R.; Takayuki, S.; Yasushi, S. Study of Si Etch Rate in Various Composition of SC1 Solution. Jpn. J. Appl. Phys. 1993, 32, L45.

(26) Sneh, O.; George, S. M. Thermal Stability of Hydroxyl Groups on a Well-Defined Silica Surface. J. Phys. Chem. A 1995, 99, 46394647.

(27) Sugaki, A.; Kitakaze, A.; Kitazawa, H. Synthesized tin and tinsilver sulfide minerals. Synthetic sulfide minerals. (XIII). Sci. Rep. Tohoku Univ., Ser. 3 1985, 16, 199-211.

(28) Abutbul, R. E.; Garcia-Angelmo, A. R.; Burshtein, Z.; Nair, M. T. S.; Nair, P. K.; Golan, Y. Crystal structure of a large cubic tin monosulfide polymorph: an unraveled puzzle. CrystEngComm 2016, $18,5188-5194$.

(29) Gullikson, E. X-Ray Attenuation Length. https://henke.lbl.gov/ optical constants/atten2.html (March 4, 2021).

(30) Sohila, S.; Rajalakshmi, M.; Ghosh, C.; Arora, A. K.; Muthamizhchelvan, C. Optical and Raman scattering studies on SnS nanoparticles. J. Alloys Compd. 2011, 509, 5843-5847.

(31) Raadik, T.; Grossberg, M.; Raudoja, J.; Traksmaa, R.; Krustok, J. Temperature-dependent photoreflectance of SnS crystals. J. Phys. Chem. Solids 2013, 74, 1683-1685.

(32) Abutbul, R. E.; Segev, E.; Argaman, U.; Tegze, A.; Makov, G.; Golan, Y. Stability of cubic tin sulphide nanocrystals: role of ammonium chloride surfactant headgroups. Nanoscale 2019, 11, 17104-17110.

(33) Moriceau, H.; Rieutord, F.; Fournel, F.; Tiec, Y. L.; Cioccio, L. D.; Morales, C.; Charvet, A. M.; Deguet, C. Overview of recent direct wafer bonding advances and applications. Adv. Nat. Sci.: Nanosci. Nanotechnol. 2010, 1, No. 043004.

(34) Grigoras, K.; Franssila, S.; Airaksinen, V. M. Investigation of sub-nm ALD aluminum oxide films by plasma assisted etch-through. Thin Solid Films 2008, 516, 5551-5556.

(35) Zur, A.; McGill, T. C. Lattice match: An application to heteroepitaxy. J. Appl. Phys. 1984, 55, 378-386.

(36) Al-Bayati, A. H.; Orrman-Rossiter, K. G.; van den Berg, J. A.; Armour, D. G. Composition and structure of the native Si oxide by high depth resolution medium energy ion scatering. Surf. Sci. 1991, 241, 91-102.

(37) Segev, E.; Abutbul, R. E.; Argaman, U.; Golan, Y.; Makov, G. Surface energies and nanocrystal stability in the orthorhombic and $\pi$ phases of tin and germanium monochalcogenides. CrystEngComm 2018, 20, 4237-4248.

(38) Kenvin, J. C.; White, M. G.; Mitchell, M. B. Preparation and characterization of supported mononuclear metal complexes as model catalysts. Langmuir 1991, 7, 1198-1205.

(39) Van Der Voort, P.; White, M. G.; Vansant, E. F. Thermal Decomposition of $\mathrm{VO}(\mathrm{acac})_{2}$ Deposited on the Surfaces of Silica and Alumina. Langmuir 1998, 14, 106-112.

(40) Nunnally, T.; Gutsol, K.; Rabinovich, A.; Fridman, A.; Starikovsky, A.; Gutsol, A.; Potter, R. W. Dissociation of H2S in non-equilibrium gliding arc tornado discharge. Int. J. Hydrogen Energy 2009, 34 (18), 7618-7625.

(41) Davydenko, L.; Mischanchuk, B.; Pokrovskiy, V.; Babich, I.; Plyuto, Y. TPD-MS and IR Studies of $\mathrm{Cr}(\mathrm{acac})_{3}$ Binding Upon CVD 
at Silica and Alumina Surfaces. Chem. Vap. Deposition 2011, 17, 123127.

(42) Puurunen, R. L. Analysis of hydroxyl group controlled atomic layer deposition of hafnium dioxide from hafnium tetrachloride and water. J. Appl. Phys. 2004, 95, 4777-4786.

(43) Nilsen, O.; Mohn, C. E.; Kjekshus, A.; Fjellvåg, H. Analytical model for island growth in atomic layer deposition using geometrical principles. J. Appl. Phys. 2007, 102, No. 024906.

(44) Hägglund, C.; Zeltzer, G.; Ruiz, R.; Thomann, I.; Lee, H.-B.-R.; Brongersma, M. L.; Bent, S. F. Self-assembly based plasmonic arrays tuned by atomic layer deposition for extreme visible light absorption. Nano Lett. 2013, 13, 3352-3357.

(45) Thangaraju, D.; Marnadu, R.; Santhana, V.; Durairajan, A.; Kathirvel, P.; Chandrasekaran, J.; Jayakumar, S.; Valente, M. A.; Greenidge, D. C. Solvent influenced synthesis of single-phase $\mathrm{SnS}_{2}$ nanosheets for solution-processed photodiode fabrication. CrystEngComm 2020, 22, 525-533. 